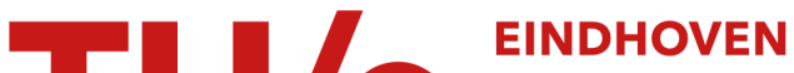 UNIVERSITY OF TECHNOLOGY
}

\section{In vitro compression of a soft tissue layer on a rigid foundation}

Citation for published version (APA):

Oomens, C. W. J., Campen, van, D. H., \& Grootenboer, H. J. (1987). In vitro compression of a soft tissue layer on a rigid foundation. Journal of Biomechanics, 20(10), 923-935. https://doi.org/10.1016/0021-9290(87)90321-6

DOI:

10.1016/0021-9290(87)90321-6

Document status and date:

Published: 01/01/1987

\section{Document Version:}

Publisher's PDF, also known as Version of Record (includes final page, issue and volume numbers)

\section{Please check the document version of this publication:}

- A submitted manuscript is the version of the article upon submission and before peer-review. There can be important differences between the submitted version and the official published version of record. People interested in the research are advised to contact the author for the final version of the publication, or visit the $\mathrm{DOI}$ to the publisher's website.

- The final author version and the galley proof are versions of the publication after peer review.

- The final published version features the final layout of the paper including the volume, issue and page numbers.

Link to publication

\section{General rights}

Copyright and moral rights for the publications made accessible in the public portal are retained by the authors and/or other copyright owners and it is a condition of accessing publications that users recognise and abide by the legal requirements associated with these rights.

- Users may download and print one copy of any publication from the public portal for the purpose of private study or research.

- You may not further distribute the material or use it for any profit-making activity or commercial gain

- You may freely distribute the URL identifying the publication in the public portal.

If the publication is distributed under the terms of Article 25fa of the Dutch Copyright Act, indicated by the "Taverne" license above, please follow below link for the End User Agreement:

www.tue.nl/taverne

Take down policy

If you believe that this document breaches copyright please contact us at:

openaccess@tue.nl

providing details and we will investigate your claim. 


\title{
IN VITRO COMPRESSION OF A SOFT TISSUE LAYER ON A RIGID FOUNDATION
}

\author{
C. W. J. OOMENS and D. H. van CAMPEN \\ Eindhoven University of Technology, Eindhoven, The Netherlands \\ and \\ H. J. Grootenboer \\ Twente University of Technology, Enschede, The Netherlands
}

\begin{abstract}
Ahstract-In vitro compression studies have been performed on layers of porcine skin and fat. The tissue layers have been loaded by means of various indentors. Indentor displacements and interstitial fluid pressures have been measured. The results have been compared to finite element calculations with mixture elements. A qualitative agreement between calculations and measurements is found. The results support the hypothesis that skin and fat behave like solid/fluid mixtures.
\end{abstract}

\section{NOMENCLATURE}

scalar

column

matrix

vector

dot product of the vectors $a$ and $b$

coordinates in tissue layer

Helmholz free energy for the solid

components of Green-Lagrange strain tensor permeability

third invariant of the deformation tensor of the solid

\section{INTRODUCTION}

In a previous publication (Oomens et al., 1987) a numerical model for skin has been proposed which is based on mixture theory. That publication describes a non-linear mixture theory and a numerical procedure based on the finite element method to solve the nonlinear field equations. In the present paper a comparison is made between the results of in vitro experiments and finite element calculations on a layer of skin and fat on a rigid foundation. This layer is loaded by various indentors to obtain different stress distributions in the tissue. The purpose of these tests is to verify the ability of the numerical model to give a realistic description of the mechanical behaviour of skin and fat, and to obtain evidence with regard to the applicability of the mixture approach for these tissues. Obtaining unified experimental conditions for such a test is a big problem. After having carried out a large number of preliminary tests to develop a correct testing procedure, we have performed six in vitro tests using three kinds of indentors. These will be described in the next section. From a numerical point of view the lack of experimental data with regard to the material properties is the biggest problem. Most data for

Received 10 June 1986; revised form 27 October 1986 material properties of skin in the literature cannot be used because the experimentalists did not rely on a mixture concept. Consequently we had to estimate a lot of the material parameter values used in the numerical model.

\section{EXPERIMENTAL SET-UP}

\section{General description}

Figure 1 gives a schematic view of the experimental set-up. A layer of porcine tissue is loaded by means of a cylindrical indentor. The layer consists of fat and skin and has the dimensions $2 L \times 2 L \times D=100 \times 100$ $\times 15 \mathrm{~mm}^{3}$. It is glued to a perspex plate. The displacements of the boundaries at $x=L$ and $x=-L$ are being suppressed by means of a square, brass frame which is attached to the skin (see Testing procedure). The tissue is loaded by three types of indentors. All indentors have a length of $40 \mathrm{~mm}$. We use a flat indentor with a width of $20 \mathrm{~mm}$ and two curved indentors with radii $R$ of $7.5 \mathrm{~mm}$ and $20 \mathrm{~mm}$ (see Fig. 1). The indentors are oblong because we want to approximate a plain strain condition beneath the midsection of the indentor. The indentors are attached to an axis that is guided by means of an air bearing and attached to a cantilever beam. The tissue is loaded by hanging weights on the cantilever beam. The displacements of the indentors are measured on the loading shaft, using a Peekel B65 inductive transducer with a range from $-1 \mathrm{~cm}$ to $+1 \mathrm{~cm}$. By means of a lucite accessory with small holes in it, needles can be inserted into the tissue at previously chosen $x, y$-positions (Fig. 2). These needles are used to position pressure catheters beneath the midsection of the indentors. The catheters are used to measure fluid pressures as a function of position and time.

During the test procedure the tissue is placed in a perspex box filled with a $(0.9 \%)$ saline solution at room temperature. 


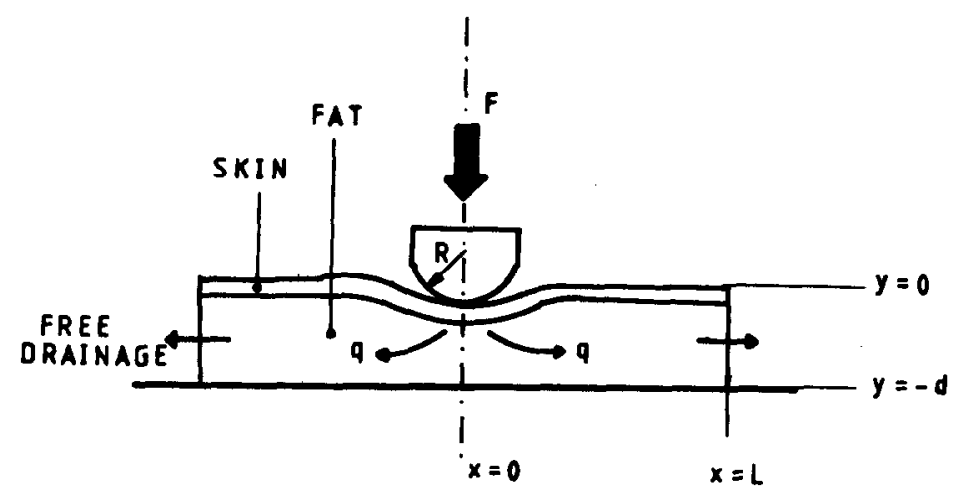

Fig. 1. Schematic view of the experimental set-up.

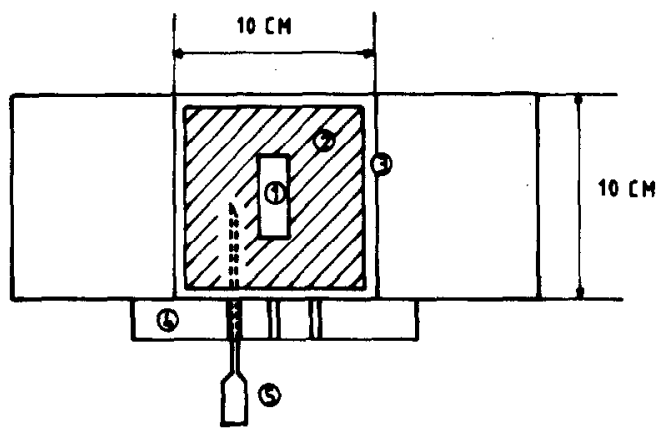

Fig. 2. Top view of the perspex plate to which the tissue is mounted. (1) Indentor, (2) porcine tissue, (3) brass frame which is fixed to the tissue by small needles, (4) lucite accessory for the insertion of spinal needles, (5) spinal needle after insertion. This needle is used to guide the catheter. When the catheter is positioned it is withdrawn.

\section{Interstitial fluid pressure measurements}

From our previous publication (Oomens et al., 1987) it is clear that tissue stress has to be divided into a solid stress and a fluid stress. In that publication it is shown that the total stress can be written as an addition of an effective stress (solid stress due to elastic deformation) and the fluid pressure. This fluid pressure can be measured.

In the last two decades a great deal of controversy has existed in the literature with regard to interstitial fluid pressure measurements. After some pioneering work in the early sixties three 'groups' of techniques have been developed: The perforated capsule method, open needle methods and the 'wick' techniques. In 1978 a symposium took place in San Diego, CA on 'Tissue fluid pressure and composition', at which most of the experts in the field were present. For a review and critical evaluation of the different techniques the reader is referred to the proceedings of this symposium (Hargens, 1981). For our purposes two techniques might be suitable. The first is the servo-null micropipette technique as developed by Wiederhielm et al. (1964) and later refined by Intaglietta et al. (1970). The method is based on a change of impedance of a micropipette, caused by a change of the location of the interface between hypertonic and isotonic saline solutions near the tip of the pipette. This change of location is caused by the interstitial fluid pressure which is to be measured. The change of impedance is used as an error signal for a servo system which compensates with an equal opposing pressure. In this way no fluid is injected in the tissue or withdrawn from the tissue. Because of the use of very small pipettes the technique hardly causes any tissue trauma. A disadvantage for our purposes was the fact that until recently it was not possible to use the technique in loaded tissue. Heineman and Grayson (1985) used polyethylene pipettes for measurements in the beating heart.

We decided to use the wick technique (Scholander et $a l ., 1968)$ because it is no problem to load the catheters and the technique is simple and reliable. The wick technique uses a flexible polyethylene tube filled with saline and connected to a pressure transducer. What makes the technique special is a woven or twined cotton thread which is pulled into the tube leaving $1 \mathrm{~cm}$ outside. This is called the wick. The purpose of the wick is to enable the saline in the catheter to make adequate contact with the interstitial space. It supports the tissues at the end of the catheter, creating saline filled cavities in equilibrium with the surrounding tissue. Disadvantages of the wick are: more tissue trauma compared to the micropipette technique and a small systematic error in the fluid pressure measurement because of osmotic effects (Snashall et al., 1971). This systematic error is small compared to the pressures we have applied to the tissues in our experiments and we have minimized the size of the catheters as far as possible. Important advantages for our purposes were the ability to load the catheters and the fact that the wick technique is easy to use.

The catheters were manufactured in the following way. Through a polyethylene tube (Portex PT46) with an inner diameter of $0.4 \mathrm{~mm}$ and an outer diameter of $0.8 \mathrm{~mm}$ a nylon fishing wire was pushed $(d=0.1 \mathrm{~mm})$. At the end of the fishing wire we tied a much thinner wire (Chromel-Allumel, $d=0.05 \mathrm{~mm}$ ) and pulled this through the tube. At the end of the $\mathrm{Cr}-\mathrm{Al}$-wire the wick 
was tied. The wick was manufactured by dismantling a 2-O-Dexon-'S'-suture wire and cutting a piece of approximately $2 \mathrm{~cm}$ off the remaining fluffy inner wire. This wick was pulled into the tube by means of the $\mathrm{Cr}$-Al-wire). This catheter fits in a 18-gauge spinal needle (Becton Dickinson) with an outer diameter of $1.25 \mathrm{~mm}$. The catheter was connected to a Gould Statham P23 GB pressure transducer. This straingauge transducer was selected for its suitability for quasi-static measurements and its low volume displacement of $0.008 \mathrm{~mm}^{3}$ at a pressure difference of $10 \mathrm{kPa}$. The whole system was filled with a $0.9 \%$ saline solution and air-bubbles were carefully removed. Before each test the system was calibrated by means of a pressure calibrater. Zero balancing was done by holding the catheter at the level at which it would be placed in the tissue.

\section{Tissue preparation}

We used skin and fat from pigs with a mass of about $100 \mathrm{~kg}$ and $16-18$ weeks old. Tissue from the scapular region was used. $\mathrm{A}$ few minutes after the animals were sacrificed a piece of skin and fat of $20 \times 15 \times 2.5 \mathrm{~cm}^{3}$ was excised from the animals. These pieces were frozen with the skin surface as flat as possible. Then they were cut into rectangular pieces of skin and fat with a thickness of $15 \mathrm{~mm}$ on a P.M.V.-Cryo-microtome. In this way we obtained six identical tissue specimens from six different pigs.

A brass frame was mounted to the tissue by pressing the needles of this frame into the tissue. After cutting away the excess tissue the remaining specimen $(10 \times 10$ $\times 1.5 \mathrm{~cm}^{3}$ ) was glued (with $\alpha$ cyanoacrylate, Permacol) on to a perspex plate. After this preparation the tissue was frozen again.

\section{Testing procedure}

After a series of preliminary tests on reproducibility we performed six in vitro tests in the following way. When the pressure measuring system was prepared, the frame with the tissue was placed in a saline solution at room temperature and thawed. Approximately $1 \mathrm{~h}$ later the catheters were inserted. At first a spinal needle with mandrin was positioned in the tissue by means of a guiding accessory. Then the mandrin was removed and the wick catheter pushed through the needle (after zero balancing). After that the needle was withdrawn, carefully preventing the catheter from changing position. When this operation was successfully completed, the catheter was tested by slightly touching the skin. When an instantaneous pressure rise was recorded the procedure was continued with the next catheter. In this way three catheters were inserted. They were all positioned at $7 \mathrm{~mm}$ below the skin surface. One catheter was placed in the symmetry plane at $x=0$ (Fig. 2), one $6 \mathrm{~mm}$ to the left and one $6 \mathrm{~mm}$ to the right. After each experimental session the position of the catheters was checked by cutting a small rectangular piece of tissue out of the specimen just beneath the loading area.
In each experiment a choice was made in advance as to the type of indentor that was used. Two experiments were performed with each type of indentor $(R=7.5$, $R=20 \mathrm{~mm}$ and the flat indentor). One experiment included seven loading cases. The tissue was loaded by hanging a calibrated mass of $200 \mathrm{~g}$ on the cantilever bcam, resulting in a load of $8 \mathrm{~N}$ on the indentor. This load was maintained during a period of $20 \mathrm{~min}$. After one loading case the tissue was allowed to relax for $2 \mathrm{~h}$. Preliminary tests showed that $2 \mathrm{~h}$ is sufficient to reach the original equilibrium position. After this relaxation period a load of $8 \mathrm{~N}$ was applied again, but the position of the tissue relative to the indentor was shifted by $2 \mathrm{~mm}$ in the $x$-direction (Fig. 1). This was done three times to the left of the symmetry plane and three times to the right. In preliminary tests no significant changes in pressures or displacements could be measured due to the asymmetry introduced by this shifting. Because of this the pressure transducers occupied different positions with regard to the indentor in each test, thus covering a range of $-12<x$ $<12 \mathrm{~mm}$ while the position of the catheters in the tissue was maintained. In this way the total test procedure on one specimen lasts $14 \mathrm{~h}$. Each loading case furnishes three pressure/time characteristics and one displacement/time curve.

\section{NUMERICAL STUDIES}

\section{Preliminaries}

It will be clear that the lack of experimental data needed for a theoretical study is a big problem. Most experimental work on skin was inspired by visco elastic models and is hard to use with a mixture model. In the next section we have described, how we estimated a property set for skin and fat based on some experiments from our group (Oomens et al., 1985) and data from the literature. It seems that the estimate is good enough to allow a qualitative comparison between theory and experiment.

Another difficulty that we encounter is given by the boundary conditions near the indentor surface. These need special consideration, which is dealt with later.

\section{Problem definition}

The solid phase of both skin and fat are considered to be purely elastic. The behaviour of both tissues can be described by means of an exponential strain energy law as proposed by Fung (1973). We have chosen to simplify the strain energy law from Fung in the twodimensional case to (Oomens et al., 1985)

$$
A^{s}=C \exp \left(a_{1} E_{11}^{2}+a_{2} E_{22}^{2}+a_{3} E_{12}^{2}+2 a_{4} E_{11} E_{22}\right)
$$

where $A^{s}=$ Helmholtz free energy for the solid; $E_{i j}$ $=$ components of the Green-Lagrange strain tensor according to a base along the symmetry planes of an orthotropic material. 
Another simplification is the assumption of initial isotropic behaviour, so $a_{1}=a_{2}$. Utilizing the results from biaxial experiments on rabbit skin by Lanir (1979), we assumed values for $a_{4}$ and $a_{3}$ to be $a_{4}=0.35$ $a_{1}$, and $a_{3}=0.32 a_{1}$. In our first studies we used for both skin and fat $a_{1}=14.6$ and $C=6.5 \times 10^{3} \mathrm{~N} \mathrm{~m}^{-2}$ (Oomens et al., 1985).

For the permeability we generalized the empirical relation for articular cartilage used by Mow et al. (1980) to large strains as follows

$$
K=K_{o} \exp M\left(J_{3}-1\right)
$$

where $K_{o}=$ permeability before deformation; $M$ $=$ non-dimensional parameter; $J_{3}=$ third invariant of the deformation tensor for the solid. As a first approximation we have used $k_{o}=1.4 \times 10^{-14} \mathrm{~m}^{4} \mathrm{~N}^{-1} \mathrm{~s}^{-1}$ and $M=10$. These are estimated from confined compression experiments (Oomens et al., 1985) on porcine skin. The studies with the flat indentor were used to verify whether the results from numerical calculations were near experimental values. From our first studies it appeared that:

the total system was too stiff;

large deformations near the edge of the indentor caused numerical problems due to the high values of $a_{1}$ and $M$ in the exponents;

the consolidation process progressed too slowly.

Because we wished to remain as close as possible to the measured properties of skin we decided to reduce the influence of the exponents without altering the product $C a_{1}$ and the value of $K_{o}$. In this way numerical problems were avoided and the behaviour of skin at small deformations was still realistic. To reduce the stiffness of the whole system we decreased the value of $C$ for subcutaneous fat. For the permeability $K_{o}$ of fat we decided to use an experimental value given by Guyton and Scheel (1966) for the subcutaneous tissue of a dog. This yielded the property set in Table 1. Summarizing the above we can state that

Both tissues are considered to be isotropic;

The influence of non-linear properties is reduced;

It is likely that the solid phase of the fat is less stiff compared to skin and the permeability is much higher.

The property set from Table 1 yields a displacement-time curve for the flat indentor problem which fits fairly well on the experimental curve.

For each indentor-tissue configuration we used a different finite element mesh, because we refined the mesh in those regions where we expected large pressure gradients. (For the flat indentor near $x=10 \mathrm{~mm}$; for the curved indentors near $x=0$.)

Table 1.

\begin{tabular}{lcccccccc}
\hline & $\begin{array}{c}C \\
\left(\mathrm{Nm}^{-2}\right)\end{array}$ & $a_{1}$ & $a_{2}$ & $a_{3}$ & $a_{4}$ & $\left(\mathrm{~m}^{4} \mathrm{~N}^{-1} \mathrm{~s}^{-1}\right)$ & $M$ \\
\hline Skin & $1 \times 10^{5}$ & 1 & 1 & 0.32 & 0.35 & $1.4 \times 10^{-14}$ & 6 \\
Fat & $0.8 \times 10^{5}$ & 1 & 1 & 0.32 & 0.35 & $320 \times 10^{-14}$ & 6 \\
\hline
\end{tabular}

The total number of elements that were used ranged from 300 to 380 , depending on the type of problem. The size of the smallest elements was $0.42 \times 0.42 \mathrm{~mm}^{2}$. For the indentors solid elements were used with a very high stiffness (Young's modulus $10^{10} \mathrm{Nm}^{-2}$ ). The thickness of the skin layer was taken to be $3 \mathrm{~mm}$. From the length of the experimentally used indentors a load per unit length was calculated of $100 \mathrm{~N} \mathrm{~m}^{-1}$. The displacements of the boundary at $y=-15 \mathrm{~mm}$ are being suppressed. Displacements of the boundaries $x=0$ and $x=50 \mathrm{~mm}$ are suppressed in the $x$-direction. The surfaces $y=0$ and $y=-15 \mathrm{~mm}$ are taken to be impermeable for the fluid, whereas the surface at $x=50 \mathrm{~mm}$ has free drainage conditions, which means that $p=0$. The surface at $x=0$ is not permeable because of symmetry conditions. Because of symmetry only half of the configuration is taken for computation. The symmetry-plane is located at $x=0$. The load is applied in 4-7 time increments using a total time interval of $0.17 \mathrm{~s}$. After $0.17 \mathrm{~s}$ the load is kept constant. In this way the first $668 \mathrm{~s}$ of the total load history are calculated in 50 increments (= time steps).

In the next section the boundary conditions in the contact area will be treated.

\section{Boundary conditions in the contact area}

The boundary conditions in the contact area require some extra consideration. In some way we have to incorporate the restriction that a point from the indentor is not allowed to penetrate into the tissue. Apart from that it is necessary that the tissue has the ability to locally slide along the indentor surface when there is no friction. For this purpose we have used a contact element developed by Schouten (1981) at the Eindhoven University of Technology. This element can be used in a situation where there is no friction; also it is suitable for use with large displacements.

Consider two bodies $V$ and $W$ that are allowed to make contact (Fig. 3). The distance between a boundary point $P$ of body $V$ to a boundary point $Q$ of body $W$ is given by

$$
u=\left(\mathbf{x}_{p}-\mathbf{x}_{q}\right) \cdot \mathbf{n}
$$

where $\mathrm{x}_{p}$ and $\mathrm{x}_{q}$ are the position vectors of $P$ and $Q$, whereas $\mathbf{n}$ is the unit normal on the boundary plane of $W$ in the point $Q$.

One can imagine a spring between the contact points $P$ and $Q$. The spring can be characterized as is

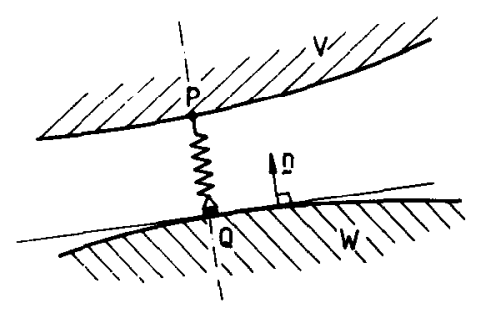

Fig. 3. Definition of the contact area. 
illustrated in Fig. 4; it has no stiffness when there is no contact $(u>0)$, and an infinite stiffness when the bodies make contact $(u \leqslant 0)$.

We have used a five-node element to characterise these 'springs' (Fig. 5). The element has three nodes on one body and one node, the contact point, on the other body. The characteristic of the spring is a constraint to the integrated equilibrium equations and is incorporated by means of a Lagrangian multiplier. This extra degree of freedom is attached to a fifth 'dummy' node, which means that it has no geometrical meaning. In each iteration of the solution process a test is performed whether the two bodies are able to make contact somewhere in the shaded area (Fig. 5). This area is determined by two lines perpendicular to the line segments 1-2 and 2-3 thereby dividing both segments in half. When node 4 lies somewhete within the shaded area, the element is switched on and works as the earlier mentioned spring. When 4 lies outside the shaded area the element does not contribute to the equilibrium equations.

It is possible to define a number of contact elements which overlap (Fig. 6). These elements have node $P$ in common but their base nodes are shifted along the contact area. In this way $P$ is allowed to make contact over a large area and can also slide along the contact area.

Now it is possible to model the penetration of a curved indentor into the tissue layer. A disadvantage of these overlapping elements is a tremendous increase of

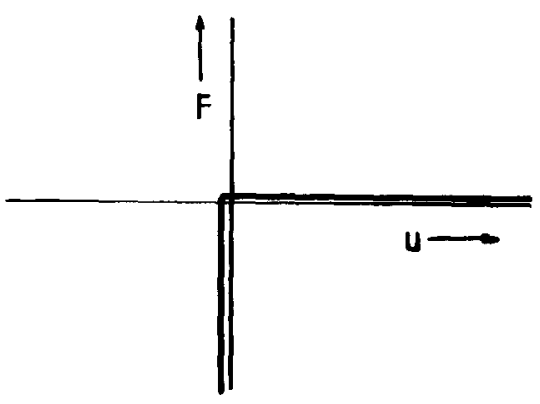

Fig. 4. Spring characteristic of the contact element. When the distance between the two bodies becomes negative the spring becomes infinitely stiff.

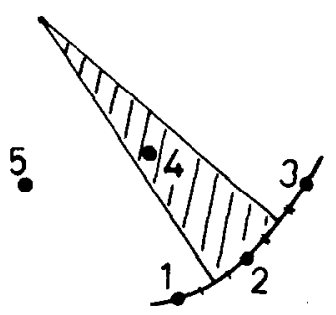

Fig. 5. Element definition and working area. When node 4 lies within the shaded area, that node can make contact with the area between 1 and 3 . Node 5 is a dummy node for an extra degree of freedom because of the Lagrange multiplier.

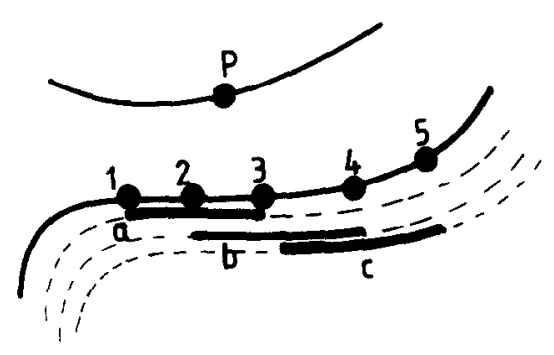

Fig. 6. Because of the overlapping elements node $P$ can make contact with the area between nodes 1-5.

the bandwidth of the stiffness matrix, resulting in a large rise of the C.P.U.-time. We have assumed that sliding of the tissue along the indentor is easy when the curved indentors are used, but not easy when the flat indentor is used. Therefore we did not use contact elements in the calculations with the flat indentor, but considered the case of infinite friction. Because of this we probably have overestimated the shear stress in the contact area in the flat indentor case. In the curved indentor cases we used the contact element with no friction. In these cases we probably have underestimated the shear stress in the contact area.

\section{RESULTS}

In this section the numerical as well as experimental results will be presented. Figure 7 shows a typical recording from one experiment. In this case the indentor with $R=20 \mathrm{~mm}$ is used. The lines (1), (2) and (3) are pressure measurements at $(-8,-8),(+4,-7)$ and $(-2,-8)$ respectively (units in $\mathrm{mm}$ ), line (D) is the displacement of the indentor. Near the arrow the paper speed is adjusted from $12 \mathrm{~s} \mathrm{~cm}^{-1}$ to $5 \mathrm{~min} \mathrm{~cm}^{-1}$. It can be seen that all pressures rise fast and then start to decrease. After the load is removed they return to zero very fast.

Figure 8 shows the displacement of the flat indentor as a function of time. The displacements at $12 \mathrm{~s}, 1 \mathrm{~min}$, $3 \mathrm{~min}, 5 \mathrm{~min}, 7 \mathrm{~min}$ and $9 \mathrm{~min}$ after load application were determined in two experimental sessions with seven loading cases in each session. A test was done whether the series of observations from the two sessions could be regarded as a selection from one random test. When this hypothesis could not be rejected $(p>0.95)$ we combined the results to the values presented in Fig. 8. It can be seen that an instantaneous displacement is found at $t=0$, followed by a creep curve. From our finite element calculations we found the solid curve in Fig. 8.

Figures 9 and 10 show the displacements of the indentors with radii of $R=20 \mathrm{~mm}$ and $R=7.5 \mathrm{~mm}$, respectively. In both cases the hypothesis, that both experimental curves are a selection from one random test had to be rejected. That is why two experimental paths are presented. These different results are probably caused by different material properties of the tissue specimen. From the solid curves in Figs 9 and 10 


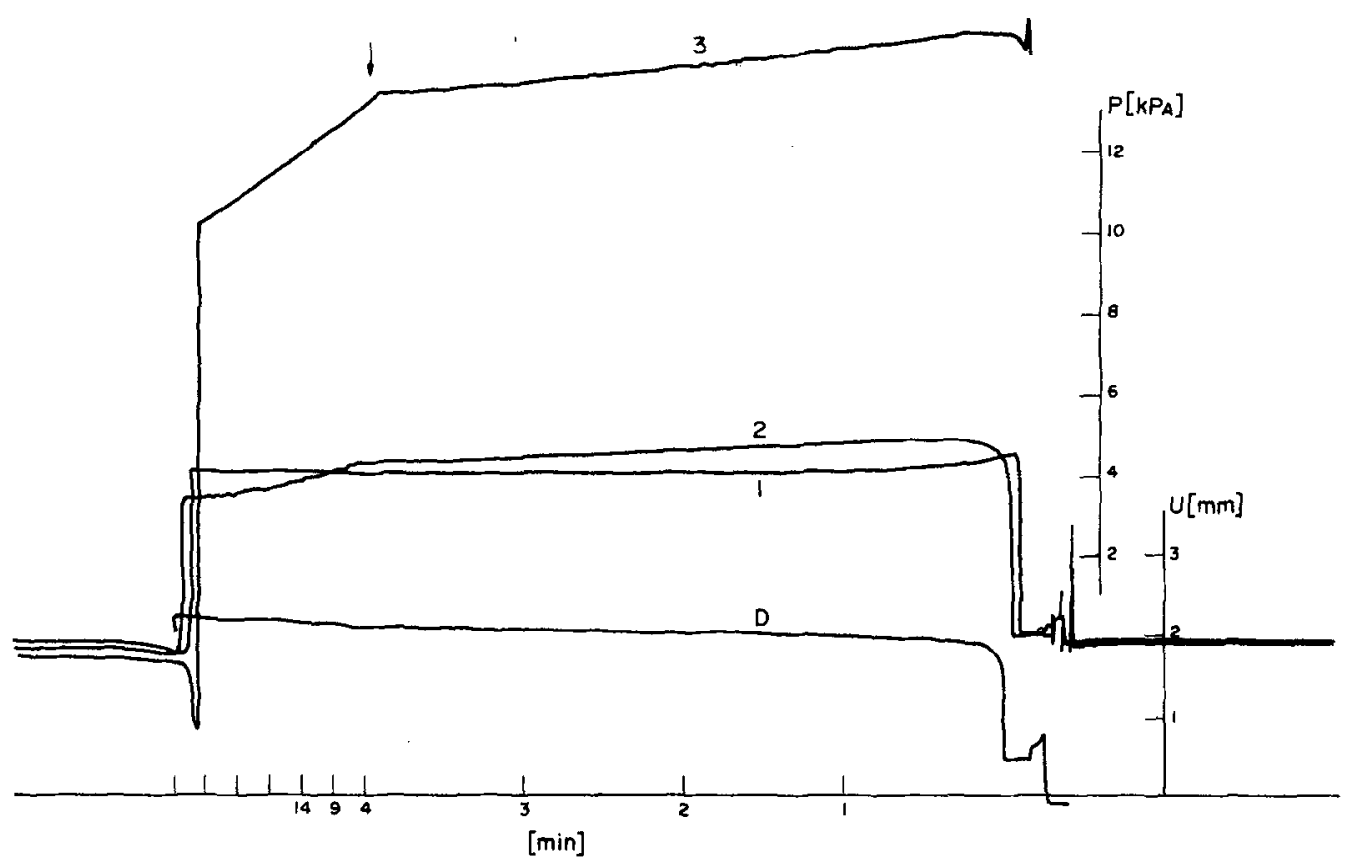

Fig. 7. A typical pressure-time and displacement-time curve for the case with an indentor of $R=20 \mathrm{~mm}$ (1) Pressure at $x=6 \mathrm{~mm}, y=-7 \mathrm{~mm}$. (2) Pressure at $x=-6 \mathrm{~mm}, y=-8 \mathrm{~mm}$. (3) Pressure at $x=0 \mathrm{~mm}$, $y=-8 \mathrm{~mm}$. (4) Displacement of the indentor.

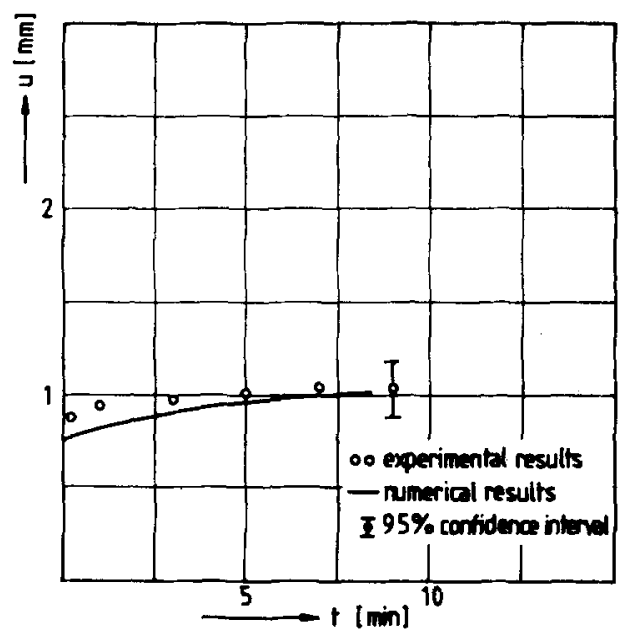

Fig. 8. Indentor displacement against time (flat indentor).

it is clear that the used property set for the solid phase is not far from reality, but the creep curve rises much to fast. It seems that the value of $K_{o}$ for the subcutaneous fat which we borrowed from Guyton and Scheel (1966) is too high.

In Fig. 11 a part of the deformed finite element mesh is shown at different times after load application. The contours are lines of equal pressures. The irregular course of the boundaries of the areas is caused by a spatial instability for small times, which disappears when time increases (Oomens et al., 1987). It can be seen that the boundaries become much smoother when time increases. The high pressure and pressure gradient near the edge of the indentor are striking. Because of the high gradient at the right of the indentor, fluid is flowing away fast and the pressure decreases. At $t=461 \mathrm{~s}$ the highest fluid pressure is no longer at the edge but a little to the left. It is also very clear that the permeability of fat was taken much higher compared to skin. So the pressure in the fat descends much faster. Another important area is the one in skin with the negative fluid pressure. This area sucks up fluid. Figure 12 shows the results for the

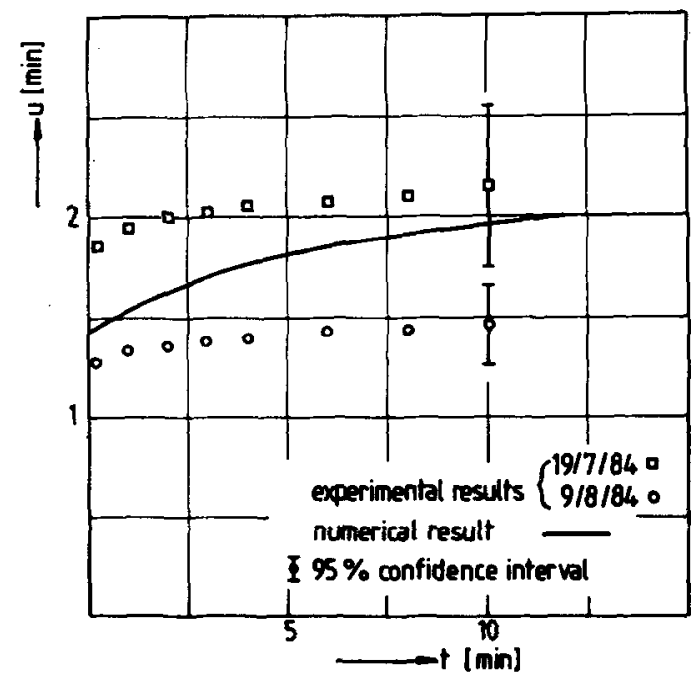

Fig. 9. Indentor displacement against time (curved indentor $R=20 \mathrm{~mm}$ ) 


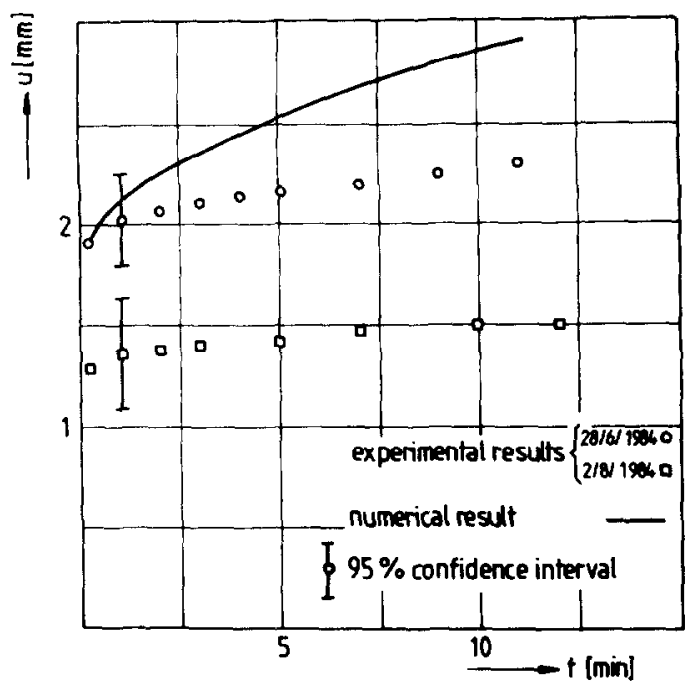

Fig. 10. Indentor displacement against time (curved indentor $R=7.5 \mathrm{~mm}$ ).

indentor with a radius of $20 \mathrm{~mm}$. The spatial instability just after load application is even more clear now. It is likely that the areas with negative pressures at $t$ $=0.168 \mathrm{~s}$, which disappear at $t=40 \mathrm{~s}$ are caused by the spatial instability and do not exist in reality. The appearance of two areas with a high fluid pressure near the contact area is amazing. These areas are also present in the first periods after load application when the indentor with $R=7.5 \mathrm{~mm}$ is used. This is shown in Fig. 13. As could be expected the maximum pressure is higher when the indentor with $R=7.5 \mathrm{~mm}$ is used than is the case when $R=20 \mathrm{~mm}$.

The reader should notice that only the first $10-15 \mathrm{~min}$ of the loading process are considered, while the total process may last for hours. Unfortunately a longer experiment was not practical because we would not have enough time to let the tissue recover. The short loading times have some consequences with regard to the comparison of experimental and numerical fluid pressures. Figures 14-16 show the numerically determined fluid pressures as a function of time where the $x$-position is used as a parameter. The $y$-position at all points is $7 \mathrm{~mm}$ below the contact area.

It is clear that each indentor gives rise to a characteristic pressure distribution. The flat indentor causes a pressure which is constant for a long time at points near the symmetry axis. At points further away from this axis the pressure starts to decrease sooner. The indentor with radius $7.5 \mathrm{~mm}$ shows a fast decrease of the pressure near the symmetry axis and a shift of the maximum pressure to later times when the distance to the axis increases. The behaviour of the indentor with $R=20 \mathrm{~cm}$ lies somewhere between the behaviour of the two earlier mentioned indentors.

It would be interesting to observe these effects in the experiment. Unfortunately the time scale as observed in Figs 14-16 is not physically real. From the displacement curves it was already clear that we have over- estimated the permeability of the subcutaneous fat. So in reality the changes in pressure are not as fast as they seem from the calculations. To observe the mentioned effects an experiment has to be performed with much longer loading times (1 h or more). For the curved indentors we did observe that at points near the indentor a maximum was reached fast but there was an enormous spread in time.

Although the pressure-time curves could not be compared it seemed reasonable to look at the maximum pressures that were reached in the observed interval of $15 \mathrm{~min}$ and to compare these. The results are presented in Figs 17-19.

It appears that the results of the flat indentor differ significantly from those of the curved indentors. This difference is shown experimentally as well as numerically.

The asymmetry in the experimental results for the indentor with $R=20 \mathrm{~mm}$ is very odd. More experiments are needed to find out whether this asymmetry is significant. However it is unlikely that such an asymmetry will occur.

It seems that the calculated pressures for the curved indentors far away from the symmetry axis are too large. This may be caused by the fact that after $15 \mathrm{~min}$ the maximum experimental pressure is not yet reached.

Despite the uncertainty in material properties a qualitative agreement exists between experiment and theory. In the next section these results will be evaluated.

\section{DISCUSSION AND CONCLUSIONS}

Some remarks on the pressure measuring technique are necessary. Although the wick technique is fairly simple to use compared to the servo-micropipette method, a great deal of skill is needed to be able to do the measurements we have described. The removal of air bubbles and the problem of obtaining a completely leak free system demand a very thorough preparation. Before each experiment we have performed tests on drift, because of leakage, and dynamic behaviour by means of a pressure calibration system. By careful preparation the technical part of the measuring system can be made leak free. However, the catheter is inserted by means of a spinal needle and this path might cause leakage along the catheter. There are two reasons why this artefact is not as bad as it seems:

The first is the elasticity of the tissue. The spinal needle does not create a hole with the same diameter as the needle, but acts as a wedge which stretches the tissue. When the needle is removed the tissue elasticity is responsible for a tight fit along the catheter which remains behind.

Because of the use of oblong indentors the highest pressure gradient is in a direction perpendicular to the indentor and thus perpendicular to the pressure catheter.

Despite this we cannot be certain that no leakage occurs along the catheters. The only way to find out 

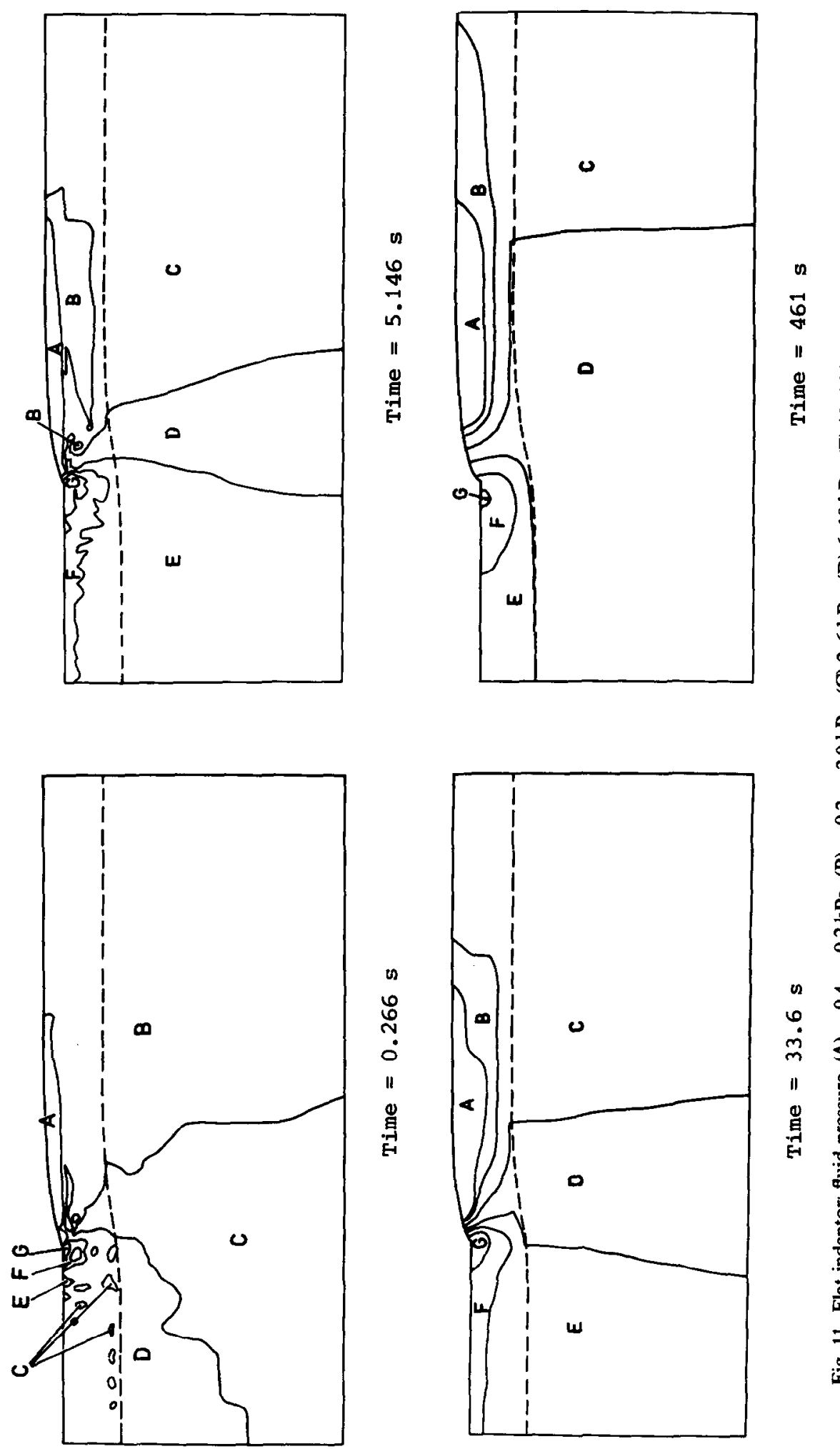

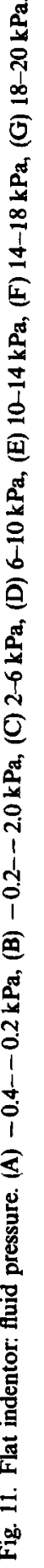



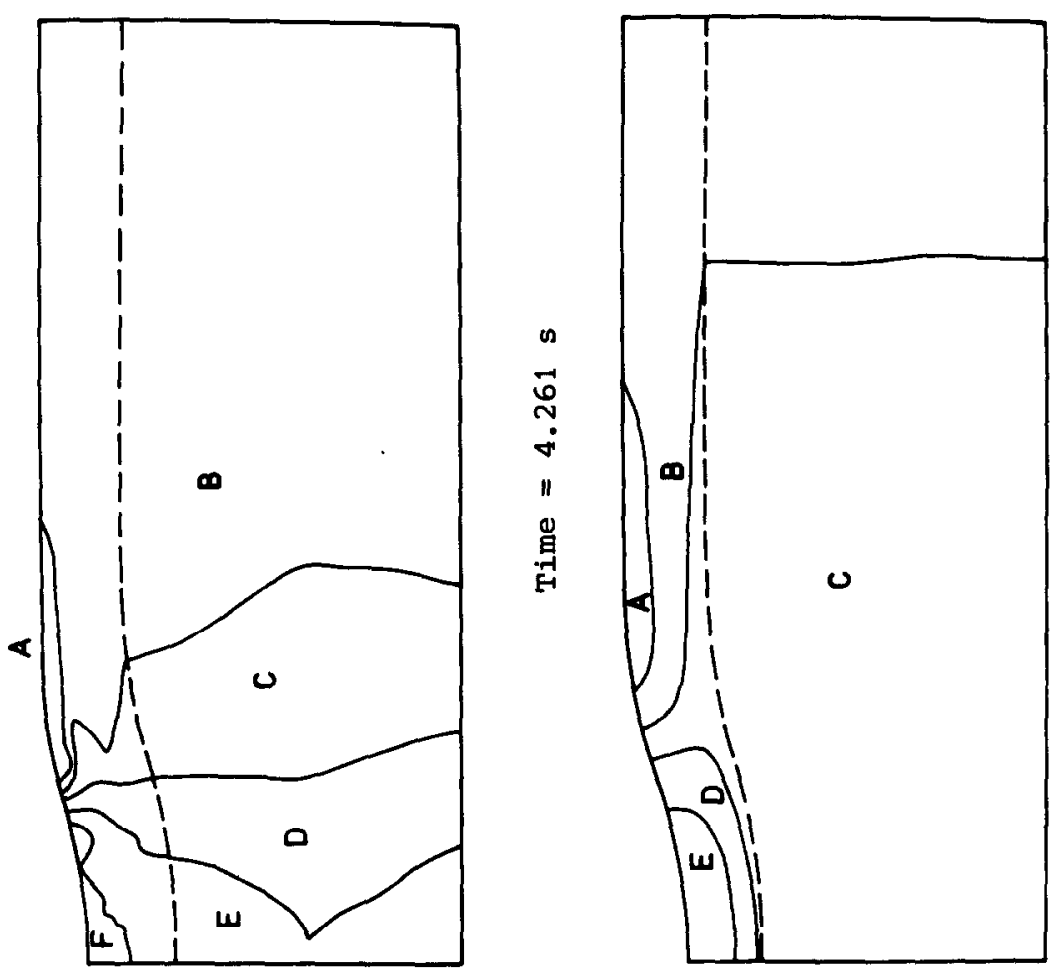

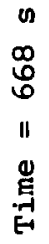

ב
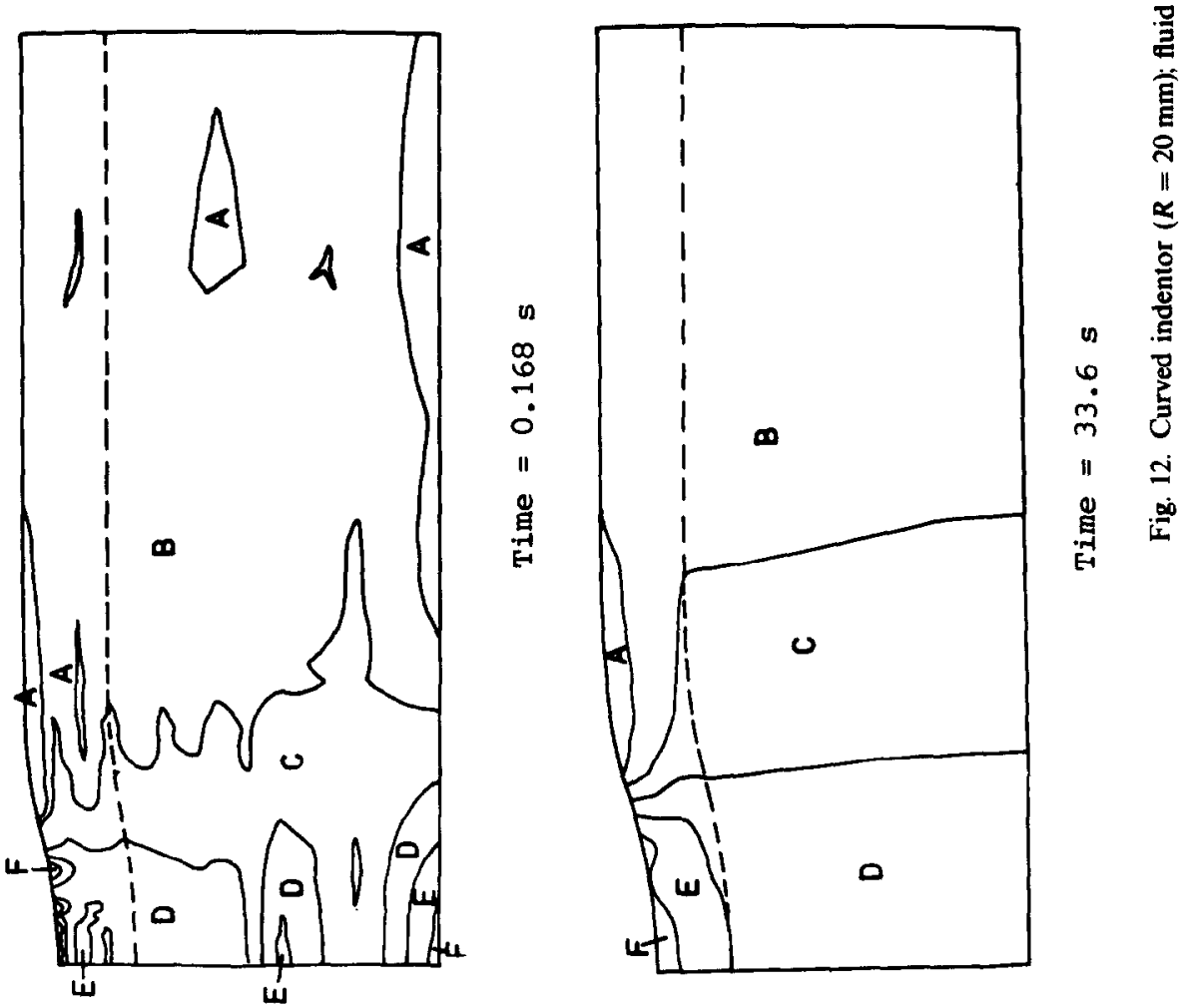

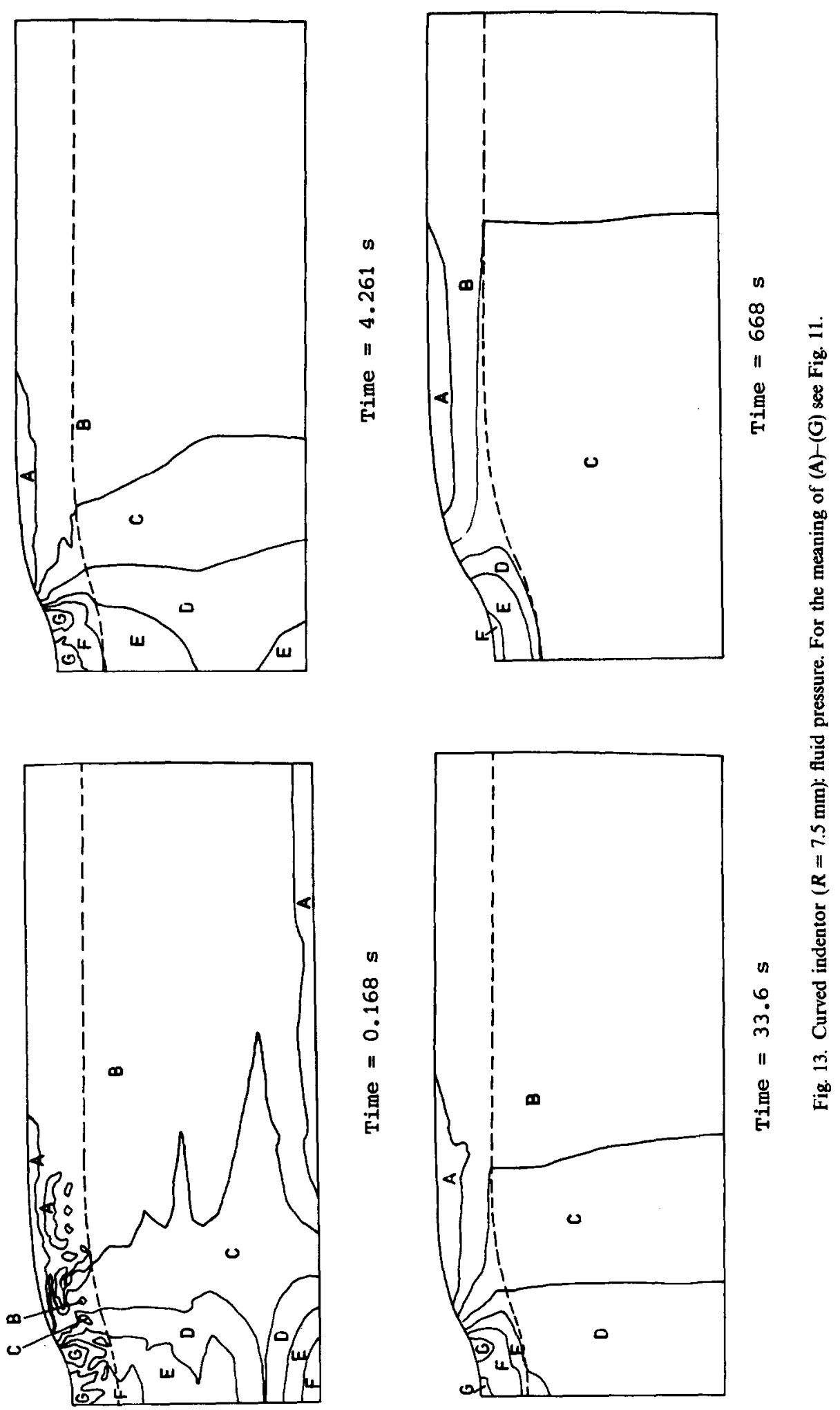


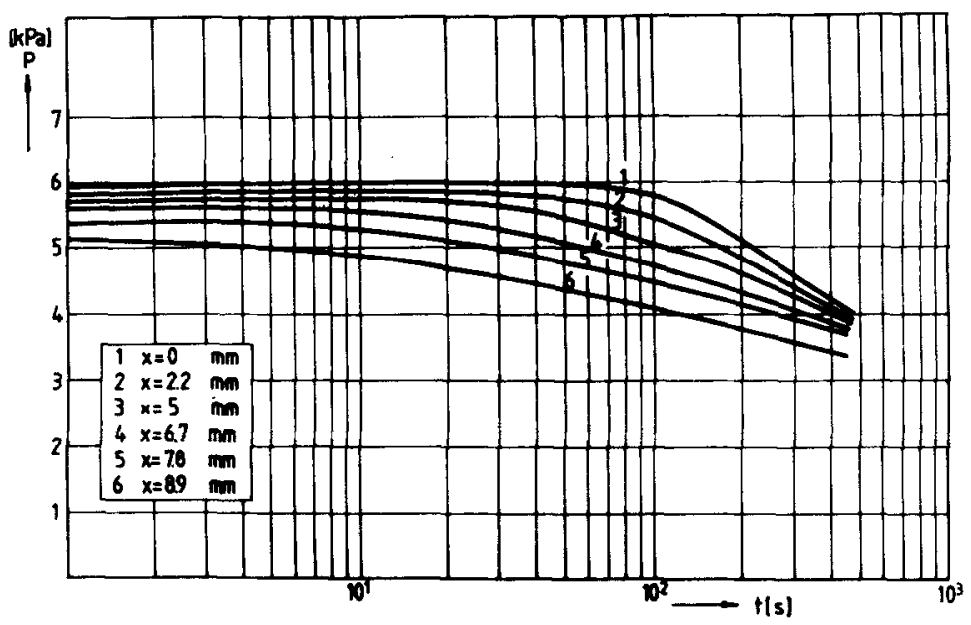

Fig. 14. Fluid pressure as a function of time at $Y=-7 \mathrm{~mm}$ (flat indentor).

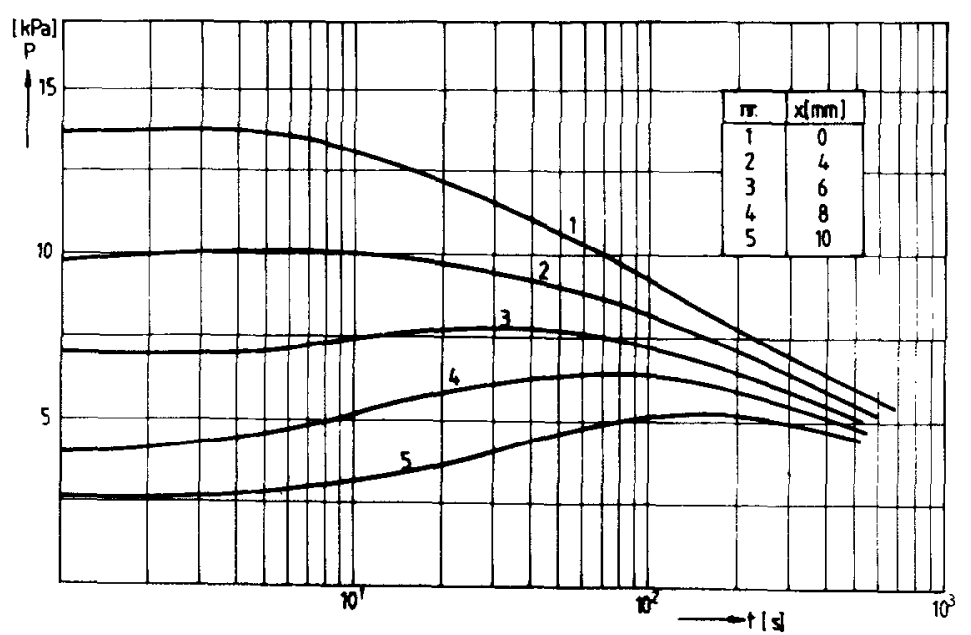

Fig. 15. Fluid pressure as a function of time at $Y=-7 \mathrm{~mm}$ (curved indentor $R=7.5 \mathrm{~mm}$ ).

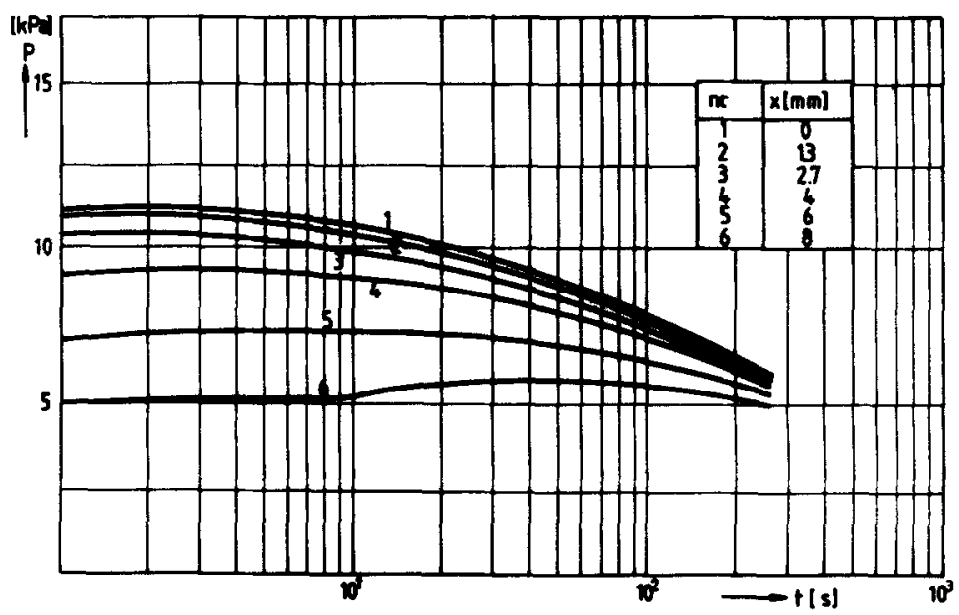

Fig. 16. Fluid pressure as a function of time at $Y=-7 \mathrm{~mm}$ (curved indentor $R=20 \mathrm{~mm}$ ). 


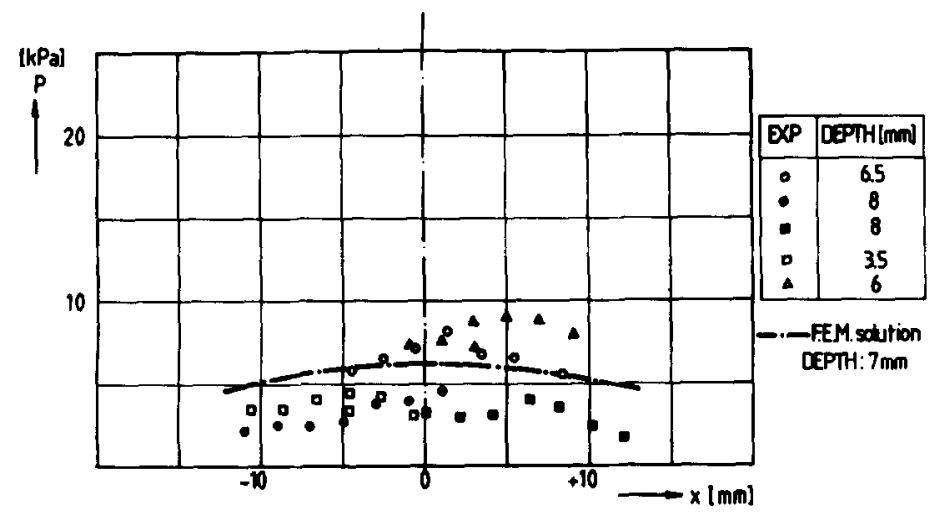

Fig. 17. Maximum fluid pressure in the time interval $0.5-1200 \mathrm{~s}$ as a function of the $x$-coordinate (flat indentor).

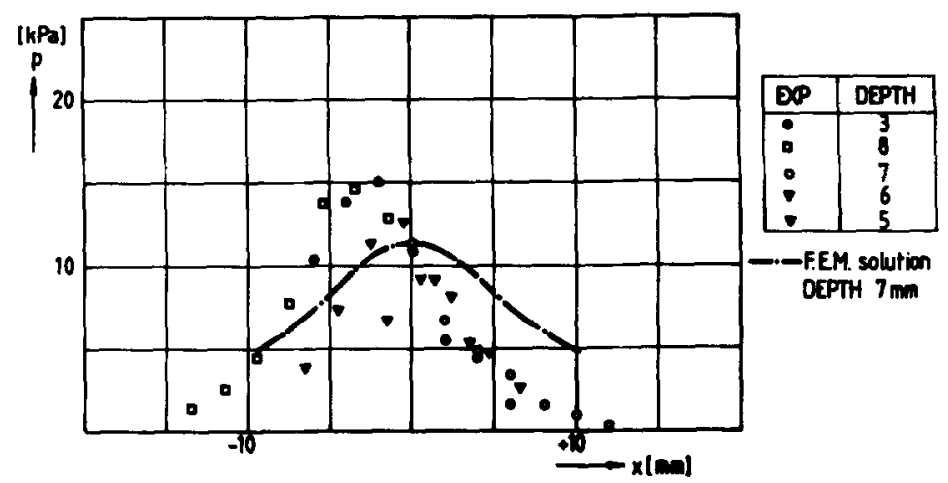

Fig. 18. Maximal fluid pressure in the time interval $0.5-1200 \mathrm{~s}$ as a function of the $x$-coordinate (curved indentor $R=7.5 \mathrm{~mm}$ ).

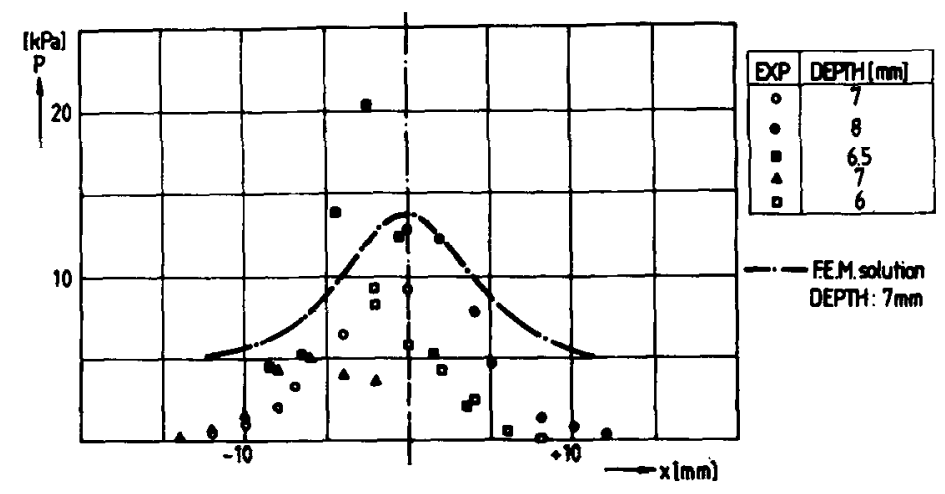

Fig. 19. Maximal fluid pressure in the time interval $0.5-1200 \mathrm{~s}$ as a function of the $x$-coordinate (curved indentor $R=20 \mathrm{~mm}$ ).

whether leakage occurs is a quantitative comparison of experimental and numerical pressure-time curves. Before this can be accomplished, tissue parameters like the permeability $K_{o}$ and the parameter $M$ (see the section Problem definition) have to be determined from different types of experiments.

Another artefact which might be important is a sensitivity of the catheters along their length, because 
tissue stress deforms the catheter. The catheters we have used have a large ratio of wall thickness against diameter $(1 / 2)$. This means that they have a high resistance against external loads. This is the reason why hardly any effect could be measured due to manipulations along the length of the catheters.

The large time constant which determines the behaviour of skin and subcutis is a practical problem with regard to the in vitro experiments.

It is certain that the estimated value for the permeability of fat that we have used is too high. For the time being it was useless to repeat the calculations with a lower permeability because this would not change the qualitative behaviour, but the spatial instability would shift to larger times. This problem can only be solved by a finer mesh, which means a tremendous rise in computer time. It is possible to improve the element with respect to this matter (see e.g. Snijders, 1986). So mesh refinement will be no problem in the nearby future.

Another very important problem is the lack of data with regard to the material properties. Because a mixture approach is used a completely different method of experimentation compared to the past is needed to obtain these properties. Part of this work is similar to the works done by Mow and co-workers for articular cartilage (Mow et al., 1984). Because of this it is very hard to come to a quantitative comparison of measurements and finite element calculations. It is clear that a mixture approach to the mechanics of skin and fat may offer a promising way of describing the mechanical behavior of these tissues. These tissues are definitely mixtures, so such an approach is based on physical reality. One of the major advantages compared to the fenomenological visco-elastic models is that mixture models open a path to physiology. Knowledge about interstitial fluid pressures and flows may be very important because they affect the homeostasis. Incorporation of microcirculation and/or lymph circulation in a mixture model is possible and useful in all kinds of applications. It has been carried out recently for microcirculation in the heart muscle by Huyghe (1986). Although a mixture model is a continuum model it has some of the advantages of structural models (physical interpretation) but it is less complicated and better suitable for structural analysis.

\section{REFERENCES}

Fung, Y. C. (1973) Biorheology of soft tissues. Biorheology 10, 139-155.

Guyton, A. C. and Scheel, K. (1966) Interstitial fluid pressure III; its effects on resistance to tissue fluid mobility. Circulation Res. 19, 412-419.

Hargens, A. R. (1981) Tissue Fluid Pressure and Composition. Williams \& Wilkins, Baltimore/London.

Heineman, F. W. and Grayson, J. (1985) Transmural distribution of intramyocardial pressure measured by micropipette technique. Am. J. Physiol. 249, H1216-H1223.

Huyghe, J. M. R. J. (1986) Non-linear finite element models of the beating left ventricle and the intramyocardial coronary circulation. Ph.D. thesis, Eindhoven University of Technology, Eindhoven, The Netherlands.

Intaglietta, M., Pawula, R. F. and Tompkins, W. R. (1970) Pressure measurements in the mammalian microvasculature. Microvasc. Res. 2, 212-220.

Lanir, Y. (1979) Biaxial stress-strain relationship in the skin. Israel J. Technol. 17, 1-12.

Mow, V. C., Kuei, S. C., Lai, W. M. and Armstrong, C. G. (1980) Biphasic creep and stress relaxation of articular cartilage in compression. J. biomech. Engng 102, 73-84.

Mow, V. C., Holmes, M. H. and Lai, W. M. (1984) Fluid transport and mechanical properties of articular cartilage: a review. J. Biomechanics 17, 377-394.

Oomens, C. W. J., Campen, D. H. van and Grootenboer, H. J. (1985) Experimental and theoretical compression studies on porcine skin. Biomechanics; Current Interdisciplinary Research (Edited by Perren, S. M. and Schneider, E.) pp. 227-232. Martinus Nijhoff, The Hague.

Oomens, C. W. J., Campen, D. H. van and Grootenboer, H. J. (1987) A mixture approach to the mechanics of skin. $J$. Biomechanics 20, 877-885.

Scholander, P. G., Hargens, A. R. and Miller, S. L. (1968) Negative pressure in the interstitial fluid of animals. Science 161, 321-328.

Schouten, R. Y. (1981) The mechanical function of the meniscus in the knee joint (in Dutch). Report WE 81-01, Eindhoven University of Technology, The Netherlands.

Snashall, P. D., Lucas, J., Guz, A. and Floyer, M. A. (1971) Measurement of interstitial 'fluid' pressure by means of a cotton wick in man and animals: an analysis of the origin of the pressure. Clin. Sci. 41, 35-53.

Snijders, H. (1986) The mechanical behaviour of soft biological tissues based on a mixture model (in Dutch). Internal Report WFW 86-011, Eindhoven University of Technology, Eindhoven, The Netherlands.

Wiederlielm, C. A., Woodbury, J. W., Kirk, S. and Rushmer, R. F. (1964) Pulsatile pressures in the microcirculation of frog's mesentery. Am. J. Physiol. 207, 173-176. 